\title{
Knee arthrodesis for a congenital luxation with Larsen syndrome
}

\author{
Mustafa Kaynak, Duncan E Meuffels
}

Orthopaedic Surgery, Erasmus MC, Rotterdam, The Netherlands

\section{Correspondence to \\ Mustafa Kaynak;}

mustafa_kaynak@|ive.nl

Accepted 17 March 2020

Check for updates

(C) BMJ Publishing Group Limited 2020. No commercial re-use. See rights and permissions. Published by BMJ.

To cite: Kaynak M, Meuffels DE. BMJ Case Rep 2020;13:e232109. doi:10.1136/bcr-2019232109

\section{SUMMARY}

A 31-year-old woman with known Larsen syndrome presented with congenital chronic luxation of her right knee with increasing instability symptoms, which limited her daily activities. We refrained from a constrained knee arthroplasty due to her relatively young age and decided to perform a knee arthrodesis. Knee arthrodesis is a viable lifelong-lasting operative treatment alternative for specific instability-related knee disease. The knee arthrodesis was performed by double plating with an additional fixation of the patella. At 1-yearfollow-up, she was able to walk without limitations and did not experience any pain with complete consolidation of the arthrodesis. At 2-year follow-up, she performed all her daily activities without limitations. Both the Knee injury and Osteoarthritis Outcome Score (KOOS) and the International Knee Documentation Committee subjective knee form (IKDC) improved at 2-year follow-up (KOOS: 61.3; IKDC: 56.3) compared with 1-year follow-up (KOOS: 52; IKDC: 40.2).

\section{BACKGROUND}

Larsen syndrome is an extremely rare congenital syndrome with a prevalence of approximately 1-9:1 000000 , whereas the life expectancy is not affected. ${ }^{1}$ Larsen syndrome is caused by a mutation in the gene encoding filamin $\mathrm{B}$, which is among others involved in bone development and more specifically of the human growth plate chondrocytes. ${ }^{2}$ Symptoms emerge at a young age, which typically involve joint or skeletal abnormalities such as knee deformities and hip dislocations. ${ }^{3}$ The existing literature regarding the optimal surgical treatment of (chronic) knee luxation in patients with Larsen syndrome is very rare and therefore experience with this condition and evidence for best treatment are extremely limited. A case report in which a constrained total knee endoprosthesis was implemented showed a complication-free period in the first month postoperatively. ${ }^{4}$ No other studies were found in which surgeons chose for a knee arthrodesis, which is a lifetime solution and knowledge of this technique is dwindling. To the best of our knowledge, this is the first study describing the knee arthrodesis concerning knee luxation in a patient with Larsen syndrome.

\section{CASE PRESENTATION}

A 31-year-old woman diagnosed with Larsen syndrome presented with congenital chronic luxation of the right knee with increasing pain and instability symptoms. The diagnosis of Larsen syndrome was made shortly after birth due to her musculoskeletal deformities. She presented with bilateral knee dislocations and hip dislocation. Her growth and development were mainly characterised by physical restrictions. Her first (orthopaedic) surgery was already at the age of 3 years. Between her third and ninth year, she underwent a total of seven orthopaedic surgeries. Throughout her years of life, she endured mostly physical limitations such as not able to work out and also limitations in her daily activities such as household activities. Moreover, she experienced recurrent luxations of both hips. After multiple surgeries, she was able to continue walking and perform her daily activities. However, for a year she had increasing instability symptoms of her right knee, which made it more and more difficult for her to walk. She has been unable to bend her right knee for her whole life and had a leg length discrepancy of approximately $5 \mathrm{~cm}$ at the expense of her right leg. There were no other deformities reported in her family. More specifically, no other family members were diagnosed with Larsen syndrome or other diseases with skeletal deformities.

\section{INVESTIGATIONS}

The patient height is $170 \mathrm{~cm}$, while her weight is $78 \mathrm{~kg}$.

The diagnosis of Larsen syndrome was made shortly after birth in Russia, our patient did not visit a clinical geneticist in the Netherlands to reconfirm the diagnosis. The specific symptoms of Larsen syndrome we found in our patient were skeletal deformities and joint dislocations. We examined the patient several times in our outpatient clinic and did not observe other pathognomonic features of the Larsen syndrome.

More specifically, she did not have cardiovascular abnormalities, facial deformities, curved spine and hearing loss.

Concerning the skeletal deformities: at physical examination, her proximal tibia was luxated and translated anteriorly. Knee flexion/extension was $5 / 0 / 5$. Varus and valgus instabilities in extension were up to $20^{\circ}$. The length discrepancy was $5 \mathrm{~cm}$ at the expense of her right leg. Plain radiographs (shown in figure 1) show anterior dislocation and shortening of the knee joint with an anterior and rotational shift of the tibial plateau towards the femur and a malformation of both the distal femur and the proximal tibia. The rotated tibial plateau moves alongside the anterior side of the femur 


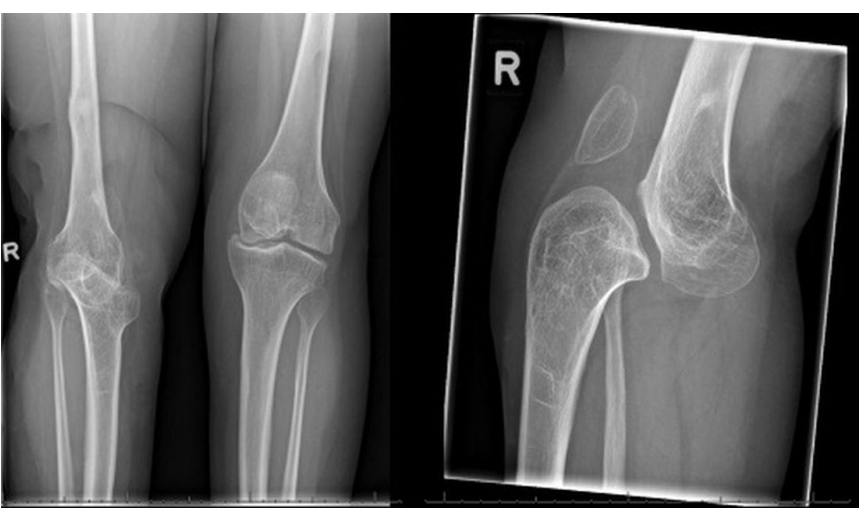

Figure 1 Weight-bearing anterior-posterior and lateral plain radiograph of the right knee showing anterior dislocation of the knee joint with an anterior, medial and rotational shift of the tibial plateau.

condyles with the presence of a dysplastic patella. Radiological signs of osteoarthritis were absent.

\section{TREATMENT}

Initially, we took a conservative approach and decided to treat the symptoms with a knee brace. However, this was insufficient in reducing symptoms and the patient still experienced knee complaints and limitations in her daily activities. Therefore, we discussed and chose for a surgical approach. Surgical options were discussed within our orthopaedic department to approach the problem. Evidence-based decision-making was based primarily on experience-based preferences in the group as the literature for surgical solutions in long-term existing knee dislocation was scarce. ${ }^{56}$ Our patient was already very limited in extending her knee because of her congenital birth defect and already underwent several surgeries before she first was treated at our hospital. While a primary knee arthroplasty replacement is an excellent procedure to improve someone's functions, we restrained from this method. Primarily, due to her instability, we would have to place a constrained knee prosthesis, which would increase the failure rate due to loosening and an unpredictable functional outcome as the patient had not flexed her knee in her lifetime. Second, because of her relatively young age, a knee prosthesis has an estimated lifetime of 10-20 years, ${ }^{7}$ thus probably leading to more surgeries in the future, with each upcoming surgery becoming more and more difficult because of scarring tissue left from the previous surgery. Also keeping in mind that our patient had undergone seven surgeries before, we wanted to conserve her for more exhausting surgeries in the future.

We offered to perform an arthrodesis with double plate fixation of her right knee (intraoperative images are shown in figure 2). ${ }^{8}$ A tibial tuberosity osteotomy was performed, since the extensor apparatus was very rigid and there was limited surgical exposure. The osseous cuts were made using knee prosthesis saw guides to control varus/valgus alignment and to control sagittal alignment. Realigning the femur and tibia increased the leg length

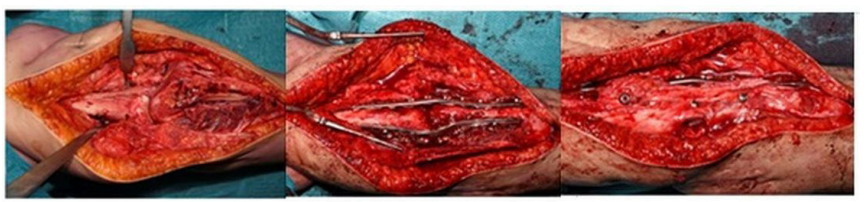

Figure 2 Intraoperative images of arthrodesis (with double plate fixation) of the right knee.
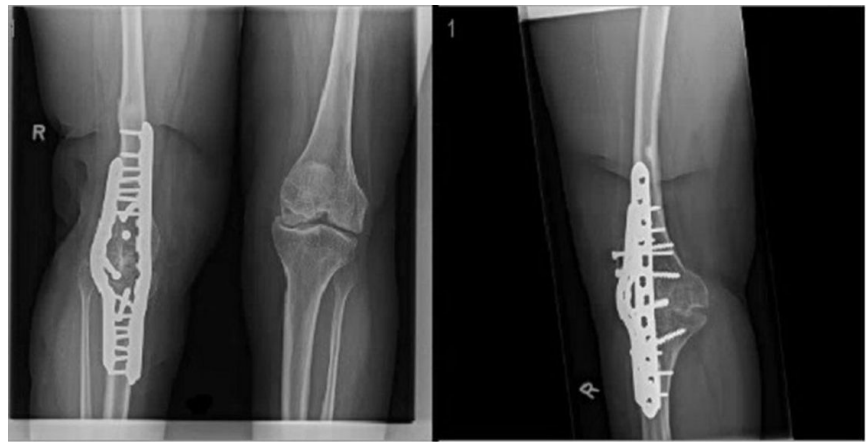

Figure 3 Plain radiographs 1 year postoperatively after arthrodesis of the right knee.

by approximately $2 \mathrm{~cm}$. Internal fixation with compression was accomplished by double plating with cortical screws to fixate the distal femur to the proximal tibia with an additional fixation of the patella with spongiosa screws. ${ }^{8}$

\section{OUTCOME AND FOLLOW-UP}

The follow-up treatment consisted of 6 weeks of plaster cast nonweight-bearing, which was extended to full weight-bearing in the following 6 weeks. Overall, her gait improved and was able to cover larger walking distances without crutches. However, she still experiences limitations in some activities, mainly due to the leg discrepancy of approximately $3 \mathrm{~cm}$. While her right leg remains in extension due to the multiple surgeries, she endures much less pain and less instability. She remained complication free in the follow-up period at 2 weeks, 6 weeks, 3 months, 6 months, 1 year and 2 years after surgery. She gradually but increasingly improved physically during each follow-up period with commencing consolidation of the tibial femoral arthrodesis at 6 weeks. At 6 months, she was able to walk up to 2-3 hours a day, exercise three times a week, while being pain free. At both 1-year and 2-year follow-up, she was able to walk without limitations and almost did not experience any pain. Moreover, there was a complete consolidation of the arthrodesis at 1-year follow-up (plain radiographs are shown in figure 3). Also, she was very satisfied with the outcome and had even fewer symptoms when standing on her operated knee compared with the other knee. We also calculated the Knee injury and Osteoarthritis Outcome Score (KOOS) and the International Knee Documentation Committee subjective knee form (IKDC) (Dutch translation) at 1-year and 2-year follow-up. ${ }^{9} 10$ The KOOS is scored with five different categories (symptoms, pain, function in daily living, function in sports and recreational activities, quality of life) and IKDC (function and activity of daily living; pain and sport activities) with scores varying from 0 to 100 in which 100 is the optimal score. The overall KOOS was 52 at 1-year follow-up and improved to 61.3 at 2-year follow-up. IKDC at 1-year follow-up was 40.2 and improved to a score of 56.3 at 2-year follow-up.

\section{DISCUSSION}

The literature concerning surgical treatment of Larsen syndrome is very rare and therefore there is no consensus in which surgical treatment would be the preferred method in these patients.

Knee arthroplasty is a highly successful, worldwide performed surgical method for treating various knee pathologies, with osteoarthritis being the main indication, however, it also has its downsides as it is not a lifetime lasting intervention with an increased risk of revision surgery especially after constrained 
knee arthroplasty. ${ }^{711}$ Knee arthrodesis is usually considered as an ultimate refuge after the failure of knee arthroplasty. ${ }^{12}$ Contraindications for knee arthrodesis include contralateral knee or hip arthrodesis and advanced osteoarthritis of the hip or ankle. ${ }^{13}$ Since our patient was relatively young of age and strict contraindications were absent, we decided to perform a knee arthrodesis to prevent revision surgery in the future. ${ }^{14}{ }^{15}$ Knee arthrodesis in our patient showed both clinically and patient satisfactory results with consolidation of the knee joint.

\section{Patient's perspective}

I am very satisfied with the surgical outcome, looking back at the 2-year period after surgery. I am nearly symptom free in my daily activities.

\section{Learning points}

- While Larsen syndrome is a rare congenital disorder, orthopaedic surgeons and healthcare providers should be aware of possible underlying congenital disease when patients present with (congenital) knee luxations.

- The existing literature does not provide consensus, mainly due to lack of studies, concerning the optimal surgical treatment for (chronic) knee luxation in patients with Larsen syndrome.

- Knee arthrodesis in our patient showed both clinically and patient satisfactory results with consolidation of the knee joint at 1-year follow-up.

- While knee arthroplasty is the preferred surgical technique in various knee disorders, knee arthrodesis should be considered in young patients with congenital knee luxations, mainly because it is a result of skeletal dysplasia.

Contributors MK and DEM contributed to the following: substantial contributions to the conception or design of the work, or the acquisition, analysis or interpretation of data. Drafting the work or revising it critically for important intellectual content.
Final approval of the version published. Agreement to be accountable for all aspects of the work in ensuring that questions related to the accuracy or integrity of any part of the work are appropriately investigated and resolved.

Funding The authors have not declared a specific grant for this research from any funding agency in the public, commercial or not-for-profit sectors.

Competing interests None declared.

Patient consent for publication Obtained.

Provenance and peer review Not commissioned; externally peer reviewed.

\section{REFERENCES}

1 Robertson S. Autosomal dominant Larsen syndrome. Available: https://www.orpha. net/consor/cgi-bin/OC_Exp.php?lng=EN\&Expert=503

2 Krakow D, Robertson SP, King LM, et al. Mutations in the gene encoding filamin B disrupt vertebral segmentation, joint formation and skeletogenesis. Nat Genet 2004;36:405-10.

3 Laville JM, Lakermance P, Limouzy F. Larsen's syndrome: review of the literature and analysis of thirty-eight cases. J Pediatr Orthop 1994;14:63-73.

4 Müller M, Strecker W. [Congenital knee dislocation in Larsen syndrome treated by arthroplasty]. Orthopade 2010;39:444-8.

5 Matthai T, Bhowmick K, Boopalan PRJVC, et al. Neglected anterior dislocation of the knee with common peroneal palsy. Case Rep Orthop 2015;2015:174965.

6 Jabalameli M, Bagherifard A, Hadi $\mathrm{H}$, et al. Total knee arthroplasty for chronic anterior knee dislocation. Clin Med Insights Case Rep 2018;11:1179547618782882.

7 Rand JA, Trousdale RT, Ilstrup DM, et al. Factors affecting the durability of primary total knee prostheses. J Bone Joint Surg Am 2003;85:259-65.

8 Anon. Campbell's operative orthopaedics. 13 edn. Elsevier, 2016.

9 Haverkamp D, Sierevelt IN, Breugem SJM, et al. Translation and validation of the Dutch version of the International knee documentation Committee subjective knee form. Am J Sports Med 2006:34:1680-4.

10 de Groot IB, Favejee MM, Reijman M, et al. The Dutch version of the knee injury and osteoarthritis outcome score: a validation study. Health Qual Life Outcomes 2008;6:16.

11 Mortazavi SMJ, Molligan J, Austin MS, et al. Failure following revision total knee arthroplasty: infection is the major cause. Int Orthop 2011;35:1157-64.

12 Gottfriedsen TB, Schrøder HM, Odgaard A. Knee arthrodesis after failure of knee arthroplasty: a nationwide register-based study. J Bone Joint Surg Am 2016;98:1370-7.

13 Somayaji HS, Tsaggerides $\mathrm{P}$, Ware HE, et al. Knee arthrodesis-a review. Knee 2008;15:247-54

14 Gathen M, Wimmer MD, Ploeger MM, et al. Comparison of two-stage revision arthroplasty and intramedullary arthrodesis in patients with failed infected knee arthroplasty. Arch Orthop Trauma Surg 2018;138:1443-1452.

15 MacDonald JH, Agarwal S, Lorei MP, et al. Knee arthrodesis. J Am Acad Orthop Surg 2006;14:154-63.

Copyright 2020 BMJ Publishing Group. All rights reserved. For permission to reuse any of this content visit

https://www.bmj.com/company/products-services/rights-and-licensing/permissions/

BMJ Case Report Fellows may re-use this article for personal use and teaching without any further permission.

Become a Fellow of BMJ Case Reports today and you can:

- Submit as many cases as you like

- Enjoy fast sympathetic peer review and rapid publication of accepted articles

- Access all the published articles

- Re-use any of the published material for personal use and teaching without further permission

\section{Customer Service}

If you have any further queries about your subscription, please contact our customer services team on +44 (0) 2071111105 or via email at support@bmj.com.

Visit casereports.bmj.com for more articles like this and to become a Fellow 